\title{
E-mentoring entre Professores e Alunos na EaD: um Estudo de Caso na Graduação em Administração de uma Instituição Pública Federal
}

\section{E-mentoring among Professors and Students on E-learning: This Case Study is about a Degree Course of Business Administration at Public Institution}

${ }^{1}$ Pesquisadora, Programa de Pós-Graduação em Administração - PROPAD da Universidade Federal de Pernambuco-UFPE. Av. dos Funcionários, s/n, 50740-580 - Recife - PE - Brasil.

marcella.ariana@hotmail.com

2 Professor, Departamento de Ciência da Informação - DCI da Universidade Federal de Pernambuco - UFPE. Av. da Arquitetura, s/n, 50740-550 Recife - PE - Brasil. silviodepaula1@gmail.com

${ }^{3}$ Professor, Departamento de Ciências Administrativas - DCA da Universidade Federal de Pernambuco - UFPE. Av. dos Funcionários, s/n, 50740-580 - Recife - PE - Brasil. jrcm@ufpe.br

${ }^{4}$ Professora, Faculdade EuropeiaFEPAM. Rua Candido Ferreira, 343, 51160-350 - Jaboatão dos Guararapes - PE - Brasil. andrezza.marianna@gmail.com
Marcella Arianna Pinto de Oliveira', Sílvio Luiz de Paula*2, José Ricardo Costa de Mendonça ${ }^{3}$, AndrezzaMarianna Pinto de Oliveira ${ }^{4}$

\section{Resumo}

Busca-se neste trabalho sobre Educação a Distância compreender como se configuram as relações de e-mentoring entre professores e alunos no curso de graduação em Administração a distância oferecido por uma instituição pública federal brasileira. Como arcabouço teórico aborda-se o conceito de mentoria, suas características, funções e fases. Aborda-se ainda e-mentoring e Educação a Distância com suas características e relações. Realizou-se um estudo de caso; as técnicas de coleta foram entrevistas online com professores/alunos, observação nãoparticipante e análise documental, estudando-se os dados por meio de análise de conteúdo. Os resultados indicam que as relações de mentoria estabelecidas entre tutores e alunos configuram-se como e-mentoring, já que os tutores são mais acessíveis aos alunos e mantêm uma comunicação mais frequente, tanto por meio de diversas ferramentas de comunicação quanto por meio de encontros presenciais, além de fornecer apoio profissional e pessoal aos alunos. Já a relação estabelecida entre professores e alunos se configura como um outro tipo de relação, que não é de mentoria, pois as características não se enquadram nos conceitos desse construto.

Palavras-chave: Educação, Educação a Distância (EAD), Ensino superior, Mentoria, E-mentoring. 


\section{E-mentoring among Professors and Students on E-learning: This Case Study is about a Degree Course of Business Administration at Public Institution}

\section{Abstract}

In this research about e-learning, we try to understand how the e-mentoring relationship among Tutors and Students works in a Business Administration course offered at distance by a public Brazilian institution. As theoretical approaches, it is observed the concept of mentoring, its features, functions and phases. It also covers e-mentoring and distance education with its characteristics and relationships. A case study was made, the data collection techniques were an online interview with tutors/students, non-participative observation and documental analysis on 'content analysis' theory. The results demonstrate that the mentoring relationship between Tutors and Students can be defined as e-mentoring: they are accessible to the students and keep intense communication on face-to-face meetings and also by the online tools provided on the course platform. On the other hand, the relationship established by Tutors and Students cannot be defined by e-mentoring due to lack of connections on the e-learning concepts.

Keywords: Education, E-learning, Graduation degree, Mentoring, E-mentoring.

\section{Introdução}

As universidades possuem diversas funções, dentre elas a função pedagógica do ensino, da produção e disseminação do conhecimento, e a social. A função social merece destaque, já que permeia todas as relações estabelecidas entre os agentes participantes na atividade do ensino (Gil, 2009). Nesse contexto, o papel do professor é desafiar, estimular e ajudar os alunos na construção de uma relação com o objeto de aprendizagem e ao mesmo tempo atender às necessidades socialmente existentes numa formação universitária (Anastasiou, 2003). Diante do exposto, professores e alunos percebem a sala de aula como um local propício para a satisfação de muitas necessidades, sendo a socialização uma delas; no entanto, alguns desses relacionamentos são efêmeros, mas outros são muito envolventes e duradouros (Gil, 2009); nessas relações o professor passa a ser um modelo de identificação para os alunos; o relacionamento firmado entre professores e alunos, em conjunto com o processo educativo, ajuda o aluno na realização de ações responsáveis, como cidadãos historicamente situados (Vergara, 2007).

Os professores do ensino superior desempenham papéis diversos devido à sua profissão, dentre eles o papel de mentoria. A princípio, o uso de mentores no ensino se limitava à identificação de estudantes com talento ou aptidãoque recebiam destaque; assim surgia a oportunidade de trabalhar durante um tempo com profissionais da área em diversos campos de atuação. Já os mentores associados ao sistema educativo frequentemente eram considerados por sua capacidade para assessorar os estudantes em matérias específicas e em projetos especiais, ou seja, os professores mentores passam a ser requeridos pelos alunos como profissionais bem-sucedidos que podem auxiliá-los em decisões profissionais.

Segundo Shea (2001), a relação de mentoria é um método de vital importância para o desenvolvimento humano, à medida que uma das partes investe seu tempo, energia e conhecimento pessoal para prestar assistência ao crescimento e talento de outrem; o mentor exerce o papel de professor ao investir seu tempo no fornecimento de instruções e informações que influenciam na vida pessoal do mentorado (Zey, 
1991); nessa situação, o mentorado é o aluno. Apesar de grande parte da literatura tratar a mentoria como sendo um construto relacionado apenas ao ambiente empresarial, para Dawson (2007) a mentoria empresarial e a acadêmica demonstram um processo evolutivo comum, e essa sincronicidade permite uma visão estratégica das melhores práticas, dentro do ambiente acadêmico.

O professor, na condição de mentor, pode ser visto como um modelo, um indivíduo cuja experiência o aluno mentorado admira, no qual inspira-se e de quem recebe conselhos.O estudante mentorado utiliza a relação de mentoria para tirar dúvidas e desenvolver uma rede de relacionamentos, ao aumentar a conexão entre conceitos do curso e do "mundo real" (Whiting \& Janasz, 2004).

Atualmente, a relação entre professores e alunos acompanha a evolução do processo de ensino, podendo ocorrer em qualquer uma das modalidades. Segundo Moran (2002), hoje o processo de ensino pode ocorrer em três modalidades distintas: a educação presencial, a semipresencial/ bimodal (parte presencial/parte virtual) e a educação a distância (EaD).

Desta forma, ao tratar da relação de mentoria no contexto de um curso não presencial, esta passa a denominar-se e-mentoring ou mentoria online. Homitz e Berge (2008) consideram que essa relação é uma evolução natural do processo na era digital; a propósito, o e-mentoring informal provavelmente ocorreu logo que o e-mail começou a ser utilizado, ou seja, logo após a expansão e difusão do Arpanet, Usenet, Bitnet e redes no final dos anos 1970 e início dos anos 80 (Single \& Single, 2011).

Entender a relação de e-mentoring entre professores, tutores e alunos no novo contexto de ensino, na educação via internet, pressupõe estudos mais específicos e profundos na área. Assim, este estudo tem o propósito de compreender como se configuram as relações de e-mentoring entre professores e alunos no ensino de graduação em Administração num ambiente virtual oferecido por uma instituição pública federal brasileira.

\section{Referencial teórico}

\subsection{Mentoria}

A mentoria é "como uma relação interpessoal original entre dois indivíduos, o mentor e o mentorado" (Whiting \& Janasz, 2004, p. 276). Tradicionalmente é uma relação entre um mais velho e experiente (mentor) e outro mais novo e com menos experiência (mentorado) para supostamente auxiliar no desenvolvimento da carreira do mentorado ou entre profissionais mais antigos, experientes, que protegem os indivíduos recém-chegados nas organizações (Shea, 2001) ou ainda professores, conselheiros ou patrocinadores (Higgins \& Kram, 2001).

A mentoria pode ser formal ou informal. A relação de mentoria formal é aquela designada por uma organização ou desenvolvida pelo indivíduo como uma atividade voluntária, a qual exige acompanhamento; a mentoria informal corresponde à relação que se desenvolve espontaneamente entre pessoas com interesse em comum, não é conduzida por organizações (Chao, Walz\& Gardner, 1992). Apesar de a teoria de mentoria estar mais relacionada com o ambiente de trabalho, voltada para as organizações, formas de mentoria têm sido associadas com a carreira acadêmica (Bierema \& Merriam, 2002).

O relacionamento de mentoria é um processo complexo no qual o mentor e o mentorado desempenham papéis e responsabilidades diferentes; assim, o êxito em qualquer orientação depen- 
de do comportamento de ambos (Allen, 2007). O mentor disposto a manter uma relação de mentoria fornece apoio ao mentorado por meio de um conjunto de comportamentos, que podem ser divididos em funções de carreira e funções psicossociais (Turban \& Lee, 2013). Tais funções diferenciam a relação de mentoria de outros tipos de relação desenvolvidos no ambiente de trabalho (Kram, 1985).

As funções de carreira têm como finalidade aumentar a probabilidade de o mentorado se tornar bemsucedido profissionalmente; elas incluem atividades como patrocínio, exposição, visibilidade, coaching, proteção e tarefas desafiadoras(Turban \& Lee, 2013). As atividades da função de carreira estão detalhadas no Quadro 1.

Quadro 1: As funções de carreira

\begin{tabular}{|l|l|}
\hline \multicolumn{1}{|c|}{ Função } & \multicolumn{1}{c|}{ Descrição } \\
\hline Patrocínio & $\begin{array}{l}\text { É a atividade mais frequentemente observada; pode ocorrer tanto em conversas } \\
\text { informais quanto em reuniões formais. Percebe-se que o mentor apoia publicamen- } \\
\text { te o mentorado, ajudando-o a construir uma reputação, a tornar-se conhecido e a } \\
\text { obter oportunidades de trabalho. }\end{array}$ \\
\hline $\begin{array}{l}\text { Exposição } \\
\text { e visibilidade }\end{array}$ & $\begin{array}{l}\text { A ação é realizada pelo próprio mentorado; é o mentor quem cria oportunidade } \\
\text { para ele demonstrar suas competências e melhorar seu desempenho, direcionan- } \\
\text { do-o a assumir responsabilidades e tarefas. Os demais membros da organização } \\
\text { podem julgar o potencial dele, o que expõe o mentorado a futuras oportunidades. }\end{array}$ \\
\hline Coaching & $\begin{array}{l}\text { Possibilita ao mentorado o aumento do conhecimento e entendimento de como } \\
\text { proceder na organização. O mentor sugere estratégias específicas para cumprir } \\
\text { certas atividades do trabalho, atingir reconhecimento e para alcançar aspirações de } \\
\text { carreira; essa atividade envolve também o compartilhamento de ideias e o feedback. }\end{array}$ \\
\hline Proteção & $\begin{array}{l}\text { Essa atividade presta proteção ao mentorado por possíveis danos no contato com } \\
\text { superiores da organização. É uma atividade que pode apoiar ou abafar o indivíduo, } \\
\text { uma vez que o mentor pode proteger o mentorado de riscos desnecessários ou } \\
\text { críticas e, assim, reduzir o risco de prejuízo à sua reputação. }\end{array}$ \\
\hline \multirow{2}{*}{$\begin{array}{l}\text { Tarefas } \\
\text { desafiadoras }\end{array}$} & $\begin{array}{l}\text { O mentor permite ao mentorado desenvolver competências específicas e vivenciar } \\
\text { senso de conquista no seu papel profissional, por meio de treinamento técnico e fe- } \\
\text { edbacks de desempenho. O mentorado desenvolve habilidades técnicas e gerenciais } \\
\text { essenciais devido à atividade que encoraja o aprendizado. }\end{array}$ \\
\hline
\end{tabular}

Fonte: Baseado em Turban e Lee (2013, p.25)

As funções psicossociais têm como objetivo melhorar as competências e a identidade profissional do mentorado, incluindo atividades como modelagem de papéis, aceitação, confirmação, aconselhamento e amizade (Turban \& Lee, 2013). Em geral, essas atividades são possíveis porque pressupõem confiança e intimidade entre os envolvidos. As atividades da função psicossocial, ainda segundo Kram (1985),são possíveis devido à relação interpessoal estabelecida, que promove confiança mútua e aumento da intimidade entre mentor e mentorado. No Quadro 2 são descritas as atividades da função psicossocial. 
Quadro 2: As funções psicossociais

\begin{tabular}{|l|l|}
\hline \multicolumn{1}{|c|}{ Função } & \multicolumn{1}{c|}{ Descrição } \\
\hline Ser modelo & $\begin{array}{l}\text { Essa é atividade psicossocial mais comumente detectada. As atitudes, valores e } \\
\text { comportamentos do mentor fornecem um modelo para o mentorado; dessa forma, } \\
\text { o mentor serve como objeto de admiração e respeito, alguém que o mentorado } \\
\text { deseja tornar-se. }\end{array}$ \\
\hline $\begin{array}{l}\text { Aceitação e } \\
\text { confirmação }\end{array}$ & $\begin{array}{l}\text { O mentor fornece suporte e encorajamento ao mentorado. Possibilita que o men- } \\
\text { torado experimente novos comportamentos, criando um laço de confiança, o que } \\
\text { encoraja o mentorado a correr riscos e a se aventurar dentro do novo ambiente. } \\
\text { Ao desenvolver competência no trabalho, o mentorado se sente mais confiante e } \\
\text { aumenta sua autoestima. }\end{array}$ \\
\hline $\begin{array}{l}\text { Aconselha- } \\
\text { mento }\end{array}$ & $\begin{array}{l}\text { Por meio dessa atividade, o mentor, fazendo uso de sua experiência pessoal, ajuda } \\
\text { o mentorado em suas dúvidas pessoais, ansiedades e medos que podem afetar seu } \\
\text { desempenho no trabalho. Por esse motivo, o mentor é considerado um bom ouvin- } \\
\text { te. Ao aconselhar, o mentor se torna um confidente do mentorado. }\end{array}$ \\
\hline Amizade & $\begin{array}{l}\text { Caracterizada como interação social dentro e fora da organização; mentor e mentora- } \\
\text { do passam a compartilhar experiências pessoais e mantêm uma relação mais estreita. }\end{array}$ \\
\hline
\end{tabular}

Fonte: Baseado em Turban e Lee (2013, p.27).

A mentoria não é uma relação estática (Ragins \& Kram, 2007); de acordo com Kram (1985), são quatro as fases da mentoria: a fase de iniciação - quando a relação está começando; a fase de cultivo - que ocorre quando uma série de funções se expande ao máximo; fase de separação - que se estabelece quando a natureza da relação é alterada por mudança no contexto da estrutura organizacional e/ou por mudanças psicológicas com um ou ambos os indivíduos; e a fase de redefinição - quando a relação de mentoria se transforma em outro tipo de relação ou é inteiramente finalizada.

A fase de iniciação começa quando um dos indivíduos, ou ambos, mentor e mentorado, tentam estabelecer uma relação; dura em média de 6 a 12 meses e envolve expectativas positivas sobre o relacionamento (Turban \& Lee, 2013).

A fase de cultivo dura tipicamente de 2 a 5 anos (Turban \& Lee, 2013); durante essa fase, as expectativas positivas criadas na primeira fase são continuamente testadas (Kram, 1985). Após, em média, dois a cinco anos, a relação de mentoria evolui para a sua terceira fase, a fase de separação (Kram, 1985). Esta fase é marcada por mudanças significativas nas funções fornecidas pelo relacionamento e experiências dos indivíduos; é também um momento em que o mentorado desenvolve independência e autonomia, o que estimula mentor e mentorado a reavaliarem o valor da relação.

Algumas relações de mentoria podem chegar ao fim na fase de separação, mas aquelas relações em que as funções psicossociais são fortes podem evoluir para a fase de redefinição (Ragins \& Kram, 2007). Nesta fase, a relação de mentoria torna-se um relacionamento entre colegas ou de amizade, as funções de carreira são menos evidentes, mas alguns conselhos, e ocasionalmente o coaching, podem continuar nessa fase (Kram, 1985).

\subsection{Educação a distância e e-mentoring}

A internet possibilitou ampliar o acesso à educação, embora o seu uso nem sempre implique práticas inovadoras e nem sempre represente mudanças nas concepções de conhecimento, ensino e aprendizagem ou nos papéis do estudante e do professor. Porém, o fato de mudar o meio em que a educação e a comunicação entre estudantes e professores se realizam (agora em ambientes digitais de aprendizagem) traz algumas mudanças no ensino e na aprendizagem que precisam ser compreendidas (Almeida, 2003). 
Moore e Kearsley (2010) classificam as funções específicas do educador na EaD em quatro grupos, conforme o Quadro 3.

Quadro 3: As funções específicas do educador na EaD

\begin{tabular}{|l|l|}
\hline \multicolumn{1}{|c|}{ Funções do educador } & \multicolumn{1}{c|}{ Exemplos de atividades } \\
\hline Funções de ensino & $\begin{array}{l}\text { Elaboração material didático. Supervisão e moderação das discus- } \\
\text { sões. Supervisão dos projetos individuais e em grupo. }\end{array}$ \\
\hline $\begin{array}{l}\text { Funções de desenvolvimento } \\
\text { do estudante }\end{array}$ & $\begin{array}{l}\text { Avaliar a aprendizagem. Proporcionar feedback sobre o progresso. } \\
\text { Manter registros dos estudantes. }\end{array}$ \\
\hline $\begin{array}{l}\text { Funções de apoio ao estu- } \\
\text { dante }\end{array}$ & $\begin{array}{l}\text { Auxiliar o estudante a gerenciar seu estudo. Estimular a motivação } \\
\text { do aluno. }\end{array}$ \\
\hline $\begin{array}{l}\text { Funções de controle do } \\
\text { sistema }\end{array}$ & $\begin{array}{l}\text { Responder e encaminhar questões administrativas. Responder e } \\
\text { encaminhar questões técnicas. Responder ou encaminhar questões } \\
\text { de aconselhamento. Representar os estudantes perante a adminis- } \\
\text { tração. Avaliar a eficácia das atividades do curso. }\end{array}$ \\
\hline
\end{tabular}

Fonte: Baseado em Moore e Kearsley (2010, p.35).

A relação de e-mentoring, também denominada de mentoria online, mentoria virtual ou telementoring, é salientada por Knouse (2001, p. 166) “como uma disciplina ou corpo de conhecimento; a mentoria online ainda não evoluiu a ponto de surgir a possibilidade de críticas à sua eficácia". Para Single e Muller (2001), o e-mentoring é uma relação que se estabelece entre um indivíduo mais experiente (mentor) e um indivíduo com menor habilidade ou experiência individual (protegido), utilizando principalmente as comunicações eletrônicas, equese destina a desenvolver e fazer crescer as aptidões, conhecimentos, confiança e compreensão cultural do mentorado para ajudá-lo a ter sucesso, além de auxiliar no desenvolvimento do mentor. Foi dessas inquietações que surgiu a necessidade de estudar mais profundamente esse novo tipo de relação, em especial na relação de e-mentoring entre professor e aluno, que está sendo proliferada para atender as necessidades de adaptação à nova realidade das salas de aula, via educação a distância. Mentoria online é uma atividade em que os estudantes e outras pessoas podem desenvolver as habilidades necessárias para se preparar para competir no atual ambiente de trabalho com sucesso (Whiting \& Janasz, 2004).

Autores como Ensher e Murphy (2007) discorrem sobre e-mentoring e entendem como uma relação benéfica mútua entre um mentor e um mentorado, a qual provê novos aprendizados e suporte emocional e de carreira, assim como a relação de mentoria, no entanto, ocorre primariamente por meio de e-mail ou outra forma eletrônica como mensagens instantâneas, salas de bate-papo, espaços de redes sociais etc. Ensher, Heun e Blanchard (2003) argumentam que o e-mentoring possui vantagens como ótimo acesso aos mentores, uma vez que as barreiras geográficas e as de tempo são reduzidas; ocorre uma atenuação das diferenças devido à natureza menos intimidativa do meio; no caso de não existir contato face a face, aspectos como raça, cor, gênero, nacionalidade não influenciam na interação entre mentor e mentorado, além de ocorrer certa imparcialidade nas relações (Single \& Single, 2011). Vale ressaltar que, da mesma forma como outros processos de mentoria, o e-mentoring pode ocorrer informalmente ou como parte de um programa formal de uma organização, destacando-se que o intuito desse trabalho é estudar as relações informais de e-mentoring.

No início dos estudos sobre e-mentoring existiam preocupações sobre a eficácia da construção de relacionamentos de mentoria a distância; no entanto, pesquisas determinaram que o e-mentoring confere aos mentoradosos mesmos benefícios concedidos às orientações realizadas presencialmente (Single \& Single, 2011). Apesar de possuir vantagens como as já citadas, o e-mentoring possui algumas desvantagens que precisam ser explicitadas, como o aumento da probabilidade da comunicação assíncrona não 
ser eficaz; a relação pode demandar maior tempo para ser estabelecida, se comparada com a relação de mentoria presencial; variedade de graus de competência para uma comunicação escrita; mau funcionamento de computadores ou erros de comunicação; aumento do interesse pelo confidencial (Ensher \& Murphy, 2007). Dessa forma, estimular as relações de e-mentoring nas atividades de EaD pode trazer benefícios para todos os envolvidos no processo, pois o e-mentoring os inter-relaciona, podendo levar o aluno a se sentir mais seguro, uma vez que o suporte recebido não se resume apenas à transmissão de conteúdo, pode servir como um eficiente e efetivo método de orientação e socialização, podendo ajudar a descobrir talentos adormecidos ou não percebidos. Outra característica marcante da relação de e-mentoring é a minimização das diferenças de status, como posição hierárquica, experiências, idade (Ensher \& Murphy, 2007).

Sendo assim, uma relação de e-mentoring gera resultados positivos para todos os agentes envolvidos no processo mentor/mentorado. Dentre os aspectos relevantes para os e-mentorados estão a autoconfiança, o suporte e o encorajamento, novos aprendizados, enriquecimento acadêmico e oportunidades de se relacionar com outros. Em relação ao e-mentor, observa-se o desenvolvimento de habilidades de liderança, novos conhecimentos, senso de satisfação, oportunidade de se relacionar com outros, retenção profissional e organizacional e oportunidade de refletir. Por mais que a mentoria presencial ou a online tratem da mesma essência, ou seja, ambas consistem no desenvolvimento profissional e emocional dos mentorados, existem semelhanças e diferenças entre as duas formas de relacionamento.

Buscando sintetizar o modelo conceitual da pesquisa, ou seja, um resumo do contexto de encontros presenciais e o e-contexto que corresponde às possibilidades de interação virtual entre professores/tutores e alunos, seja por meio do AVA ou de outras ferramentas de comunicação, apresenta-se a figura a seguir.

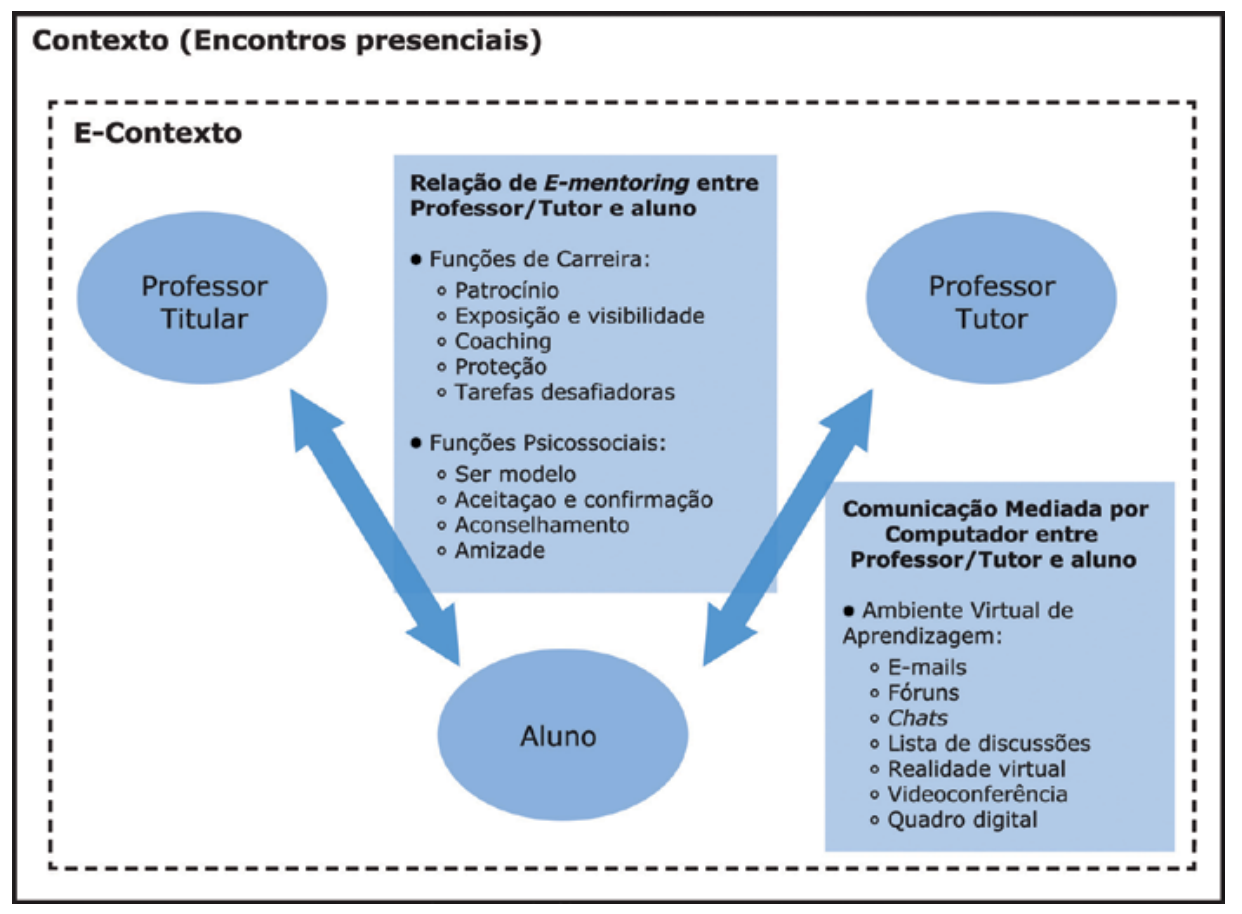

Figura 1: Modelo conceitual da pesquisa

A seguir serão descritos os procedimentos metodológicos definidos para a pesquisa.

\section{Metodologia}

Para a pesquisa, adotou-se a abordagem qualitativa para a coleta e análise dos dados; segundo Minayo (1998), a pesquisa qualitativa é importante para compreender as relações que ocorrem entre atores 
sociais tanto no âmbito da instituição quanto no de movimentos sociais e as representações de determinado grupo sobre temas específicos. Diante da proposta deste trabalho, a pesquisa qualitativa possibilita uma melhor interpretação das relações sociais firmadas entre professores titular e alunos e tutores e alunos. Como estratégia de pesquisa foi adotado o estudo de caso único (Merriam, 2002), especificamente o curso de graduação em Administração na modalidade a distância na Universidade Estadual da Paraíba (UEPB). O propósito deste trabalho é explorar a relação de e-mentoring na EaD entre professores, tutores e alunos, uma relação pouco estudada, na qual os limites ainda não estão bem definidos; dessa forma o estudo de caso único vem contribuir e auxiliar na busca pelo entendimento desses construtos. A escolha do lócus se deu por dois motivos: o primeiro deles pelo fato de o curso existir desde 2006, tempo suficiente para o estabelecimento de uma relação de mentoria, de acordo com Kram (1985); outro motivo foi a acessibilidade e a disponibilidade dos atores em participar da pesquisa.

Foram utilizadas quatro técnicas de coletas de dados concomitantemente: a primeira foi a observação não participante, na qual foram observadas, com a ajuda de um protocolo de observação, as interações realizadas entre os sujeitos de pesquisa (educadores e alunos) via chat e fórum no ambiente virtual de aprendizagem utilizado pelo curso (Moodle). A segunda técnica utilizada na pesquisa foram as entrevistas estruturadas com professores titular, tutores e alunos, em que foi aplicada a mesma entrevista com os professores e tutores e outra entrevista com os alunos; as entrevistas foram realizadas via Internet, justifica-se a escolha das entrevistas online, mais especificamente por e-mail, pelo fato de o Curso de Administração ser desenvolvido em quatro polos situados em cidades diferentes. A terceira foi a pesquisa documental, na qual foram coletados documentos como o projeto pedagógico do curso (PPC), ementas, informações obtidas no site da IES. A quarta técnica foi o uso de notas de campo, as quais consistiam de anotações realizadas pelo pesquisador durante todo o trabalho de campo.

Os dados coletados foram analisados e interpretados qualitativamente com base no referencial teórico e por meio da análise de conteúdo (Bardin, 2012). Dentre as técnicas de análise de conteúdo utilizou-se a análise por categorias, a qual se baseia na decodificação de um texto em vários elementos, que são classificados e formam agrupamentos analógicos (Richardson, 2012), correspondendo a um conjunto de elementos sob um título genérico que compartilham características comuns (Bardin, 2012).

Foram analisadas 44 disciplinas, incluindo as de reoferta. Em todo o curso foi possível identificar 3.171 fóruns (dentre eles fórum em grupo, fórum de notícias, fórum social, fórum temático e fórum com a Coordenação) e 60 chats. Todos os fóruns e chats fizeram parte da pesquisa, tendo em vista que durante as discussões nesses espaços poderiam surgir dados relevantes para a compreensão do fenômeno estudado.

Os formulários foram enviados para 284 alunos; foram obtidas respostas de 13 alunos ao formulário. O formulário foi enviado para 15 professores titulares, dos 23 do curso, tendo sido obtida resposta de 4 professores. Foram enviados formulários para todos os 20 tutores do curso; no entanto, apenas 4 tutores responderam.

\section{Resultados e discussão}

A seguir serão apresentadas as funções de carreira e psicossociais; para cada função serão apresentadas as perspectivas dos professores, dos tutores e dos alunos.

Quanto às funções de carreira, diante da perspectiva dos professores, afirmaram durante a entrevista exercer a atividade de patrocínio com os alunos, criando uma imagem positiva destes perante outros professores, tutores ou alunos. A atividade de patrocínio foi mais perceptível nos momentos em que os professores buscaram destacar determinados alunos, elogiando-os publicamente ou parabenizando por determinados comportamentos, em especial o esforço em dedicar-se às disciplinas, colaborando para a construção de reputação, autoconhecimento e credibilidade dos alunos (Kram, 1985). 
Uma característica relevante da atividade de desenvolver tarefas desafiadoras aos alunos é o feedback, que foi também desempenhado por esses professores. Quanto à tarefa de coaching, trechos transcritos representam como o indivíduo que desempenha atividades de coach se interessa significativamente e influencia o coachee sob uma perspectiva particular acerca do mundo; essa perspectiva pode reforçar a capacidade do mentoradoou não. Não foi possível identificar as demais funções de carreira na relação entre professores e alunos; em especial a atividade de proteção foi claramente eliminada pelos próprios professores.

Após explanados os resultados coletados acerca das funções de carreira na perspectiva dos professores do curso, serão abordadas as funções de carreira na visão dos tutores. Segundo estes, tentaram construir uma imagem positiva dos seus alunos para os demais professores e tutores, apesar de não terem sido verificados nos fóruns e chats comentários dos tutores que representassem tal comportamento. Quanto à atividade de tarefas desafiadoras, de acordo com os tutores eles não ofereceram esse tipo de tarefas aos alunos. Apesar de não poder propor atividades, os tutores davam feedbacks dessas atividades aos alunos.

De acordo com os tutores, eles protegeram seus alunos de possíveis críticas acerca dos trabalhos. A atividade de coaching, desempenhada pelos tutores, foi percebida durante os fóruns das disciplinas. Após explanados os resultados coletados nas funções de carreira na perspectiva dos tutores do curso, serão abordadas as funções de carreira na visão dos alunos desse mesmo curso.

Quanto à atividade de patrocínio, os alunos perceberam que seu professor/tutor buscou construir uma imagem sua positiva para os demais professores, tutores e alunos. A atividade de coaching foi percebida a partir das interações realizadas no ambiente virtual, durante os chats e fóruns. Os alunos afirmaram que a atividade de proteção foi inexistente no relacionamento entre professores/tutores. Não foi possível identificar a atividade de exposição e visibilidade na percepção dos alunos. A seguir serão explanadas as funções psicossociais nas perspectivas dos professores, tutores e alunos.

A atividade de aconselhamento foi visível nos chats; não foi possível identificar as demais funções psicossociais, funções de aceitação e confirmação e a atividade de amizade na interação entre professores e alunos; no entanto, essa característica pode ser comum, devido às inibições e disparidades que vêm prejudicar as discussões entre mentor e mentorado (Smith-Jentsch et al., 2008). A seguir serão apresentados os resultados das funções psicossociais na perspectiva dos tutores.

Os tutores afirmaram que os alunos os procuraram para conversar sobre dificuldades, e o posicionamento deles foi de total abertura aos problemas dos alunos. Durante toda a análise dos dados foi possível identificar as funções de amizade, de ser modelo, pelo discurso dos próprios alunos. Já a atividade de aceitação e confirmação foi identificada em apenas um momento por parte dos tutores; no entanto, os alunos apresentaram outras situações. Abaixo serão apresentadas as funções psicossociais na visão dos alunos.

As funções psicossociais são algumas das características que classificam a relação entre dois indivíduos como sendo uma relação de mentoria (Kram, 1985). Primeiramente foi questionado se os alunos obtiveram ajuda dos professores e tutores para solucionar problemas pessoais e profissionais; houve divergência nas respostas. Os que consideraram ter tido auxílio declararam apenas em relação às dificuldades profissionais e/ou voltadas para o ensino. Os demais, a maioria, afirmaram que receberam apoio profissional e pessoal dos professores e tutores. Novamente veio à tona a diferença entre os professores e tutores, assim como ocorreu nas funções de carreira. O Quadro 4 apresenta em resumo as funções de e-mentoring encontradas durante a relação estabelecida entre os professores e alunos durante o curso. 
Quadro 4: Funções de e-mentoring entre professores e alunos

\begin{tabular}{|c|c|c|}
\hline \multicolumn{3}{|c|}{ Funções de e-mentoring entre professores e alunos } \\
\hline $\begin{array}{l}\text { Categorias } \\
\text { analisadas }\end{array}$ & $\begin{array}{l}\text { Indicadores } \\
\text { das categorias }\end{array}$ & $\begin{array}{l}\text { Fala dos respondentes que representam } \\
\text { os indicadores }\end{array}$ \\
\hline \multirow{4}{*}{ Funções de carreira } & Patrocínio & $\begin{array}{l}\text { "Acho que você de fato tem aproveitado muito bem } \\
\text { este espaço. Continue assim" (P04); }\end{array}$ \\
\hline & Coaching & $\begin{array}{l}\text { "Sim. Esse assunto é muito importante na vida } \\
\text { pessoal e profissional, pois tenta resgatar o valor } \\
\text { das pessoas e não apenas cobrar delas (...), por isso } \\
\text { é importante termos "administradores de verdade" } \\
\text { nas empresas, pois assim teremos a certeza do } \\
\text { cumprimento da ética, por exemplo" (P05). } \\
\text { "E esquecendo do lado humano e fico me questio- } \\
\text { nando muito sobre verdade. Mas o pior é quando } \\
\text { vemos "administradores", principalmente em } \\
\text { repartições públicas, atuando de forma totalmente } \\
\text { equivocada. Isso é terrível" (A16). } \\
\text { "É verdade. A falta de compromisso é muito visível } \\
\text { nesse tipo de empresa" (P05). } \\
\text { "Sim, mas que livros você poderia me indicar? É } \\
\text { gritante" (A16). } \\
\text { "Sugiro que você comece a buscar esse tema na } \\
\text { internet nos sites de busca, pois como é um tema } \\
\text { atual, talvez não esteja em todos os livros" (P05). }\end{array}$ \\
\hline & Proteção & 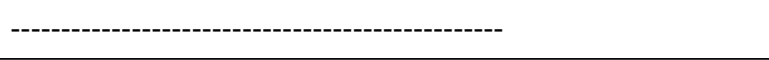 \\
\hline & Tarefas desafiadoras & $\begin{array}{l}\text { "Tiveram que resolver muitos exercícios, fazer provas } \\
\text { que eram verdadeiros testes de verificação da apren- } \\
\text { dizagem e escrever artigos" (P02). }\end{array}$ \\
\hline \multirow{4}{*}{$\begin{array}{l}\text { Funções } \\
\text { psicossociais }\end{array}$} & Ser modelo & $\begin{array}{l}\text { "Pelo profissionalismo, atenção dedicada ao aluno, } \\
\text { além do bom caráter de todos" (A06). }\end{array}$ \\
\hline & Aconselhamento & $\begin{array}{l}\text { "Sim. Na área profissional. Recebi conselhos quanto } \\
\text { aos comportamentos e objetivos no ambiente pro- } \\
\text { fissional" (A06) }\end{array}$ \\
\hline & $\begin{array}{l}\text { Aceitação } \\
\text { e confirmação }\end{array}$ & ----- \\
\hline & Amizade & -------------------------------------------------- \\
\hline
\end{tabular}

O Quadro 5 apresenta as funções de e-mentoring identificadas durante as interações entre tutores e alunos. 
Quadro 5: Funções de e-mentoring entre tutores e alunos

\begin{tabular}{|c|c|c|}
\hline \multicolumn{3}{|c|}{ Funções de e-mentoring entre tutores e alunos } \\
\hline $\begin{array}{l}\text { Categorias analisa- } \\
\text { das }\end{array}$ & $\begin{array}{l}\text { Indicadores das } \\
\text { categorias }\end{array}$ & $\begin{array}{l}\text { Fala dos respondentes que representam } \\
\text { os indicadores }\end{array}$ \\
\hline \multirow{4}{*}{ Funções de carreira } & Patrocínio & $\begin{array}{l}\text { “Olá A22, parabéns por sua participação no fórum } \\
\text { e pelo arquivo postado. Nota dez! Bons estudos!" } \\
\text { (T03). }\end{array}$ \\
\hline & Coaching & $\begin{array}{l}\text { “Estou, juntamente com toda a equipe, à dispo- } \\
\text { sição de vocês para possíveis esclarecimentos" } \\
\text { (T06). }\end{array}$ \\
\hline & Proteção & $\begin{array}{l}\text { “Às vezes eu protegia, quando eu via que } \\
\text { realmente aquela pessoa era esforçada e estava } \\
\text { batalhando pra fazer aquele trabalho" (T04). }\end{array}$ \\
\hline & Tarefas desafiadoras & ---------------------- \\
\hline \multirow{4}{*}{$\begin{array}{l}\text { Funções psicosso- } \\
\text { ciais }\end{array}$} & Ser modelo & $\begin{array}{l}\text { "Espero em breve estar preparada para futura- } \\
\text { mente assumir uma tutoria e trabalhar com esta } \\
\text { equipe que tanto admiro" (A27). }\end{array}$ \\
\hline & Aconselhamento & $\begin{array}{l}\text { "Ele foi bastante atencioso e buscou me orientar } \\
\text { e deu conselhos para possíveis soluções" (A03). }\end{array}$ \\
\hline & Aceitação e confirmação & $\begin{array}{l}\text { "O nosso sucesso está na garra e na vontade de } \\
\text { nossos tutores, em especial você, em nos apoiar, } \\
\text { nos incentivar, na compreensão pelas dificulda- } \\
\text { des, o desejo de sempre melhorar" (A28). }\end{array}$ \\
\hline & Amizade & $\begin{array}{l}\text { "Ao meu tutor } 01 \text { em especial, por estar sempre à } \\
\text { disposição tanto como tutor, quanto como amigo, } \\
\text { também um grande agradecimento, espero que } \\
\text { tenhamos sempre sua presença não só no curso, } \\
\text { mas após ele" (A25). }\end{array}$ \\
\hline
\end{tabular}

A frequência de interação na Educação a Distância é importante devido à interferência na diminuição da separação física entre professores e alunos (Mendes, 2010), principalmente quando essas interações são de qualidade. Quanto maior o contato fora da comunicação mediada pelo computador, ou seja, quanto maior contato pessoal, mais rapidamente as relações de e-mentoria podem se desenvolver. Diante das apresentações e análises realizadas, o quadro a seguir apresenta as principais características das ferramentas de comunicação encontradas no estudo.

Quadro 6: Informações relevantes sobre as ferramentas de comunicação

\begin{tabular}{|l|l|l|l|l|l|}
\hline \multirow{2}{*}{ Prof. } & \multicolumn{5}{|c|}{ Ferramentas de comunicação } \\
\cline { 2 - 6 } & $\begin{array}{l}\text { Frequência de } \\
\text { comunicação }\end{array}$ & $\begin{array}{c}\text { Tempo } \\
\text { médio }\end{array}$ & $\begin{array}{l}\text { Qualidade das } \\
\text { interações }\end{array}$ & TIC utilizadas & \multicolumn{1}{c|}{$\begin{array}{c}\text { Contato } \\
\text { Presencial }\end{array}$} \\
\hline Titular & Semanal & 6h semanais & Boas & $\begin{array}{l}\text { E-mail } \\
\text { Telefone } \\
\text { Skype }\end{array}$ & $\begin{array}{l}\text { Mensal durante } \\
\text { aulas nos polos }\end{array}$ \\
\hline Tutor & Diário & 3h diárias & Boas & $\begin{array}{l}\text { E-mail } \\
\text { Telefone } \\
\text { Skype }\end{array}$ & $\begin{array}{l}\text { Semanal no polo, } \\
\text { com possibilidade } \\
\text { de reuniões parti- } \\
\text { culares }\end{array}$ \\
\hline
\end{tabular}




\subsection{Fases da relação de e-mentoria}

Kram (1995) define que a relação de mentoria possui quatro fases. Desta forma, os alunos avaliaram em qual fase da relação de e-mentoring a relação que eles estabeleceram com professores e tutores se encontrava.

Oito dos alunos entrevistados (A02, A04, A05, A06, A07, A08, A10, A13) afirmaram que a relação estabelecida se encontrava na fase 3 , ou seja, a de separação, que possui algumas características voltadas especificamente para o indivíduo mentorado. É nesse momento da relação que o mentorado percebe que pode trabalhar de maneira mais autônoma e independente (Kram, 1985).

Dois alunos (A9, A11) afirmaram que a relação estabelecida entre professores e tutores encontrava-se na fase 1, a fase de iniciação. Os indícios corroboram a ideia, de que, assim como ocorreu com o aluno A11, a relação terminou ainda na fase de iniciação. Um dos alunos, A01, afirmou que estava na fase de cultivo, ou seja, a relação está trazendo benefícios, as funções de carreira e psicossocial ainda são frequentes (Kram, 1985). Apenas um aluno (A03) considerou que a relação firmada com o tutor, segundo suas palavras, estava na fase de redefinição, e que se transformou em uma amizade.

\subsection{Impacto da relação de e-mentoria para os alunos}

Durante a análise e discussão dos dados realizados percebeu-se o quanto os professores e tutores influenciaram a formação e desenvolvimento dos alunos durante o curso; no entanto, não apenas na formação acadêmica, alguns professores/tutores exerceram certa influência na formação profissional, de carreira desses alunos. Ainda ocorreu influência psicossocial, se levados em consideração os momentos de proximidade, aconselhamento e amizade.

Os alunos que afirmaram positivamente a existência da relação de e-mentoring com professores/tutores declaram que o contato virtual facilitou a relação, já que existiu durante todo o curso pouco tempo disponível para encontros presenciais. OQuadro 7 representa as principais características das relações firmadas entre professores e alunos e tutores e alunos.

Quadro 7: Características das relações firmadas, na percepção de cada grupo

\begin{tabular}{|c|l|l|l|l|l|}
\hline \multirow{2}{*}{$\begin{array}{c}\text { Grupo de } \\
\text { responden- } \\
\text { tes }\end{array}$} & \multicolumn{5}{|c|}{$\begin{array}{c}\text { Características das relações firmadas na percepção } \\
\text { de cada grupo }\end{array}$} \\
\cline { 2 - 6 } & $\begin{array}{c}\text { Apoio } \\
\text { profissional }\end{array}$ & \multicolumn{1}{|c|}{$\begin{array}{c}\text { Apoio } \\
\text { pessoal }\end{array}$} & $\begin{array}{c}\text { Intensidade } \\
\text { da relação }\end{array}$ & $\begin{array}{c}\text { Aspectos } \\
\text { positivos }\end{array}$ & $\begin{array}{c}\text { Relação de } \\
\text { e-mentoria }\end{array}$ \\
\hline $\begin{array}{c}\text { Professor } \\
\text { titular }\end{array}$ & $\operatorname{Sim}$ & Não & $\begin{array}{l}\text { Pouca } \\
\text { intensidade }\end{array}$ & $\begin{array}{l}\text { Nova experiência } \\
\text { e aprendizados }\end{array}$ & $\begin{array}{l}\text { Não ocorreu com } \\
\text { os alunos }\end{array}$ \\
\hline Tutor & $\operatorname{Sim}$ & Sim & $\begin{array}{l}\text { Muita } \\
\text { intensidade }\end{array}$ & $\begin{array}{l}\text { Crescimento e } \\
\text { aprimoramento } \\
\text { profissional }\end{array}$ & $\begin{array}{l}\text { Ocorreu } \\
\text { durante o curso }\end{array}$ \\
\hline Aluno & Sim & Sim & $\begin{array}{l}\text { Moderada } \\
\text { intensidade }\end{array}$ & $\begin{array}{l}\text { Desenvolvimen- } \\
\text { to na carreira e } \\
\text { pessoal }\end{array}$ & $\begin{array}{l}\text { Ocorreu com } \\
\text { forte tendência } \\
\text { em relação aos } \\
\text { tutores }\end{array}$ \\
\hline
\end{tabular}

Diante das análises e da discussão de dados apresentadas, percebe-se que o e-mentoring entre membros de universidades, em especial quando trabalhada no desenvolvimento de disciplinas com responsáveis específicos como professores e tutores, aparenta ter uma aplicação promissora (Thompsona et al., 2010), principalmente quando comparada com a relação de mentoria tradicional. 
Tendo em vista os dados apresentados e analisados, pode-se concluir que as relações de e-mentoria poderão ser firmadas com maior predisposição em relação aos tutores do que em relação aos professores. Essa diferenciação foi identificada devido a algumas características que foram encontradas durante as relações especificamente dos tutores com seus alunos, como a maior disponibilidade do tutor em manter contato mais aproximado com os alunos; comunicação diária e durante vasto tempo; utilização de vários meios de comunicação; apoio profissional e pessoal fornecido aos alunos; e os encontros presenciais semanais, com possibilidade de orientação individual. Já as relações firmadas entre professores e alunos não foi considerada como de e-mentoria, uma vez que a comunicação realizada com os professores ocorre semanalmente ou em muitos casos quinzenalmente, os professores se comunicam com os alunos por meios de comunicação restritos, o apoio fornecido aos alunos é de curto prazo, ou seja, tem como foco principal a disciplina ministrada; e não apoio profissional para a carreira do aluno; além do mais, existe a escassez de encontros presenciais, principalmente de orientações individuais.

Em se tratando da relação entre professores titulares e alunos, as atividades da função de carreira, como patrocínio, coaching e tarefas desafiadoras foram expressas por ambas as partes; quanto às funções psicossociais, pode-se perceber que as únicas funções correspondidas foram as de ser modelo e de aconselhamento. Já as funções de aceitação e confirmação e amizade estiveram mais presentes na relação entre os tutores, segundo os comentários realizados pelos próprios alunos.

Quanto à relação entre tutores e alunos, foi possível identificar as atividades da função de carreira como patrocínio, coaching e proteção. Em relação às atividades da função psicossocial, foram consideradas relações recíprocas as atividades de aconselhamento, aceitação e confirmação e amizade; já a função de ser modelo foi mencionada apenas pelos alunos, ou seja, eles consideram os tutores como modelos a serem seguidos. O Quadro 8 demonstra o resumo das funções de e-mentoring encontradas no estudo.

Quadro 8: Funções de E-mentoring identificadas por professores, tutores e alunos

\begin{tabular}{|c|l|l|}
\hline \multicolumn{3}{|c|}{ Funções de E-mentoring Curso de Administração } \\
\hline \multirow{2}{*}{ Agentes } & \multicolumn{2}{|c|}{ Funções de E-mentoring } \\
\cline { 2 - 3 } & \multicolumn{1}{|c|}{ Funções de Carreira } & \multicolumn{1}{c|}{ Funções Psicossociais } \\
\hline Professores & $\begin{array}{l}\text { Patrocínio. Coaching. Tarefas } \\
\text { desafiadoras. }\end{array}$ & Ser Modelo. Aconselhamento. \\
\hline Tutores & Patrocínio. Coaching. Proteção. & $\begin{array}{l}\text { Aconselhamento. Amizade. } \\
\text { Aceitação e confirmação. }\end{array}$ \\
\hline Alunos & $\begin{array}{l}\text { Patrocínio. Coaching. Tarefas } \\
\text { desafiadoras. }\end{array}$ & $\begin{array}{l}\text { Ser Modelo. Aceitação e } \\
\text { confirmação. Aconselhamento. } \\
\text { Amizade. }\end{array}$ \\
\hline
\end{tabular}

Resumindo as principais características da relação firmada entre os agentes, foi identificado que os professores exercem mais influência profissional sobre os alunos do que apoio pessoal; a influência profissional está relacionada ao desenvolvimento do aluno na disciplina específica do professor. Já os tutores influenciaram os alunos tanto no âmbito pessoal quanto no profissional, inclusive em aspectos relacionados à profissão e ao emprego; muito dessa ajuda surgiu pela necessidade dos alunos e pelo estreitamento da relação com os tutores.

Dessa forma, foi possível concluir que a relação estabelecida entre professores e alunos não pode ser considerada uma relação de e-mentoria, apesar de cumprir algumas funções de mentoria. Nota-se que um dos fatores que pode ter influenciado a não formação e desenvolvimento de uma relação de e-mentoring foi a pouca disponibilidade dos professores em ter um contato mais próximo dos alunos. Já as relações firmadas entre os tutores e alunos, neste estudo especificamente, correspondem, sim, a uma relação de e-mento- 
ring, uma vez que cumprem várias das funções da mentoria. Foi identificado que uma maior frequência de encontros presenciais influencia diretamente no estabelecimento da relação de e-mentoring.

Por fim, é notável a necessidade de preparação dos profissionais que irão atuar nessa nova conjuntura da educação, considerando que os conhecimentos e habilidades, em especial dos professores e tutores, precisam estar de acordo com as novas ferramentas de comunicação (Nunes, 2015), ou seja, vivenciar situações de aprendizagem com a não presencialidade física necessita de abordagem pedagógica inovadora, que venha a privilegiar a comunicação mediada pelo instrumento tecnológico, mas ao mesmo tempo que permita a relação com o outro, de forma constante no processo, o que vem a ser mais que uma descoberta (Benfatti \& Stano, 2009). Por fim, apresenta-se na figura a seguir, a partir do modelo conceitual da pesquisa com base nos achados, a adequação à realidade encontrada na pesquisa de campo.

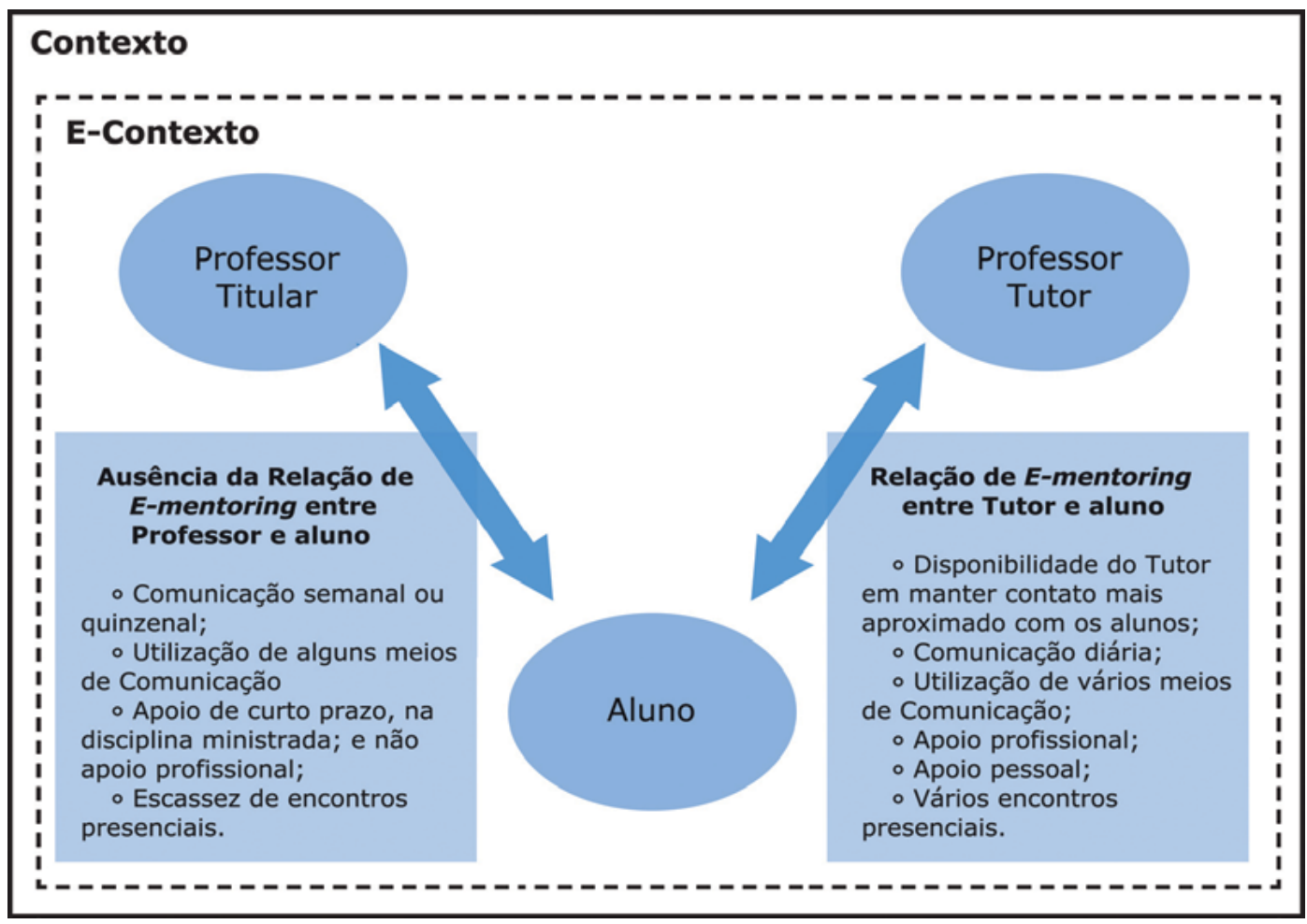

Figura 2: Modelo conceitual das relações de e-mentoring do caso estudado

\section{Considerações finais}

Pode-se concluir que no estudo realizado a relação estabelecida entre professores e alunos não pode ser considerada uma relação de e-mentoria, apesar de cumprir algumas funções de mentoria. Nota-se que um dos fatores que podem ter influenciado a não formação e desenvolvimento de uma relação de ementoring foi a pouca disponibilidade dos professores em ter um contato mais próximo dos alunos, seja pelas mídias de comunicação utilizadas, seja pelo AVA, como para encontros presenciais.

Já as relações firmadas entre os tutores e alunos, neste estudo especificamente, correspondem a uma relação de e-mentoring, uma vez que cumprem várias das funções da mentoria, e durante todo o curso foi possível perceber as interações e a abertura, por parte dos tutores,para manter proximidade com os alunos, demonstrando disponibilidade para encontros presenciais e para comunicações virtuais. Foi identificado que uma maior frequência de encontros presenciais influencia diretamente no estabelecimento da relação de e-mentoring. 
É importante destacar um assunto que foi recorrente durante o estudo: a relevância e a necessidade dos encontros presenciais, um queixa frequente entre os alunos do curso, uma vez que as relações de mentoria são mais efetivas quando os participantes se comunicam além dos meios eletrônicos (Ensher, Heun \& Blanchard, 2003). É possível considerar o modelo bimodal da tutoria -em que além da tutoria virtual existe encontros presenciais -, no qual professores e tutores podem conhecer melhor o aluno e orientá-lo de maneira particular (Gonçalves, 2007).

O aprimoramento e o desenvolvimento de relações de e-mentoring (Single \& Single, 2005) são recurso fundamental para formação de profissionais que desempenhem o papel do e-mentor bem como o aprimoramento das ferramentas de apoio (Kasprisin, Single, Single \& Muller, 2003). Deve-se levar em consideração que uma experiência ineficaz pode desencorajar um indivíduo permanentemente das relações de e-mentoring (Thompsona et al., 2010).

Tradicionalmente, as relações de mentoria ocorrem entre pessoas de maior idade para com pessoas de menor idade; diante dessa teoria, considera-se que a relação ocorre mais frequentemente entre professor e aluno, tutor e aluno. O mentor precisa ser mais experiente que o mentorado, não necessariamente mais velho. As relações de mentoria podem ocorrer também entre aluno e professor, aluno e tutor; entre tutor e professor, no entanto, com menor frequência. Apesar de este trabalho se restringir aos relacionamentos de mentoria desses, isso não significa dizer que outras relações de mentoria não sejam possíveis no contexto da EaD; assim, existe a possibilidade de relacionamento de mentoria entre professores e tutores, ou vice-versa.

Diante das interações realizadas durante um curso a distância, é possível que exista a relação de mentoria entre pares; assim, considera-se o relacionamento de mentoria entre o grupo de professores, o grupo de alunos e o grupo de tutores.

Recomenda-se que mais estudos sejam realizados sobre a relação de e-mentoring na Educação a Distância para que venha a desenvolver e aprimorar a área em questão. Sugere-se ainda que o estudo seja também realizado em outros cursos e em outros níveis de ensino, como em nível de pós-graduação. Pode-se ainda investigar as demais relações de e-mentoria descritas.

De modo geral, o trabalho buscou esclarecer o relacionamento estabelecido entre professores e alunos e entre tutores e alunos, sempre considerando as diferentes atribuições entre professores e tutores.

\section{Referências bibliográficas}

Allen, TammyD. (2007). Mentoring relationships from the perspective of the mentor. In: Ragins, Belle Rose \& Kram, Kathy (Eds.). The Handbook of mentoring at work: theory, research and practice (pp. 123-147). Thousand Oaks: Sage.

Almeida, M.E.B. (2003). Educação a distância na internet: abordagens e contribuições dos ambientes digitais de aprendizagem. Educação e Pesquisa, 29(2), 327-340.

Anastasiou, L. G. C. \& Alves, L. P. (Orgs.). (2003). Ensinar, aprender, apreender e processos de ensinagem. In: Processo de ensinagem na universidade: pressupostos para as estratégias de trabalho em aula. 9. ed. Joinville: Univille.

Bardin, L. (2012). Análise de conteúdo. Lisboa: Edições 70.

Benfatti, Eliana \& Stano, Rita. (2009). A professoralidade de uma tutoria em EaD Virtual. Manaus: Edutec.

Chao, G. T., Walz P. M. \& Gardner, P. D. (1992). Formal and informal mentorships: a comparison on mentoring functions and contrast with nonmentored counterparts. Personnel Psychology, 45(1), 619-636. 
Dawson, G. S. (2007). Involved or committed? Similarities and differences in advising and mentoring in the academic and business world. Communications of the Association for Information Systems, 20(1), 3-10.

Ensher, E. A., Heun, C. \& Blanchard, A. (2003). Online mentoring and computer-mediated communication: new directions in research. Journal of Vocation Behavior, 63(1), 264-288.

Ensher, E. A. \& Murphy, S. E. (2007). E-mentoring: next generation research strategies and suggestions. In: Ragins, B. R. \& Kram K. (Eds.). The handbook of mentoring at work: theory, research and practice. Thousand Oaks: Sage.

Gil, Antonio Carlos (2009). Didática do Ensino Superior. São Paulo: Atlas.

Godoy, Arilda Schmidt (2006). O estudo de caso qualitativo. In: Godoi, C. K., Bandeira-de-Melo, R. \& Silva, A. B. Pesquisa qualitativa em estudos organizacionais: paradigmas, estratégias e métodos (pp. 115-146). São Paulo: Saraiva.

Homitz, Daniel James \& Berge, Zane L. (2008). Using e-mentoring to sustain distance training and education. The Learning Organization of Emerald Group Publishing Limited USA, 15(1), 326-335.

Knouse, Stephen B. (2001). Virtual mentors: mentoring on the internet. Journal of employment couseling, 38(1), 162-169.

Kram, K. E. (1985). Mentoring at work: development relationships in organizational life. Lanham: University Press of America.

Kram, K. E. (1983). Phases of mentor relationship. Academy of Management Journal, 26(1), 608-665.

Merriam, S. B. (2002). Qualitative research in practice: examples for discussion and analysis. San Francisco: Jossey-Bass.

Minayo, M. C. S. (1998). O desafio do conhecimento. 5. ed. São Paulo Rio de Janeiro.

Moore, Michael G. \& Kearsley, Greg. (2010). Educação a distância: uma visão integrada. São Paulo: Cengage Learning.

Moran, J. M. (2002). Contribuições para uma pedagogia da educação on-line. In: Silva, Marco. Educação online: teorias, práticas, legislação, formação corporativa. São Paulo: Loyola.

Nunes, Ivânio Barros (2015). A história da EAD no mundo. In: Litto, Frederic Michael \& Formiga, Marcos (eds.). Educação a distância: o estado da arte (pp. 02-08). São Paulo: Pearson.

Ragins, B. R \& Kram, K. (2007). The roots meaning of mentoring. In: Ragins, B. R. \& Kram K. (Eds.). The handbook of mentoring at work: theory, research and practice. Thousand Oaks: Sage.

Richardson, Roberto J. (2012). Pesquisa social: métodos e técnicas. São Paulo: Atlas.

Shea, G. F. (2001). Mentoring: como desenvolver o comportamento bem-sucedido do mentor. Rio de Janeiro: Qualitymark.

Single, Peg\& Muller, Carol (2001). Electronic mentoring: issues to advance research and practice. Annals of Procedings of the Anual Meeting of the International Mentoring Association,12(1) 234-250.

Single, P. B. \& Single, R. M. (2011). Mentoring and the technology revolution: how face-to-face mentoring sets the stage for e-mentoring. In: Kochan, F. K. \& Pascarelli, J. T. Creating successful telementoring programs Greenwich (pp. 7-27). Information Age Press. 
Smith-Jentch, Kimberly, Scielzo, Shannon, Yarbrough, Charlyl\& Rosopa, Patrick. (2008). A comparison of face-to-face and electronic peer-mentoring: Interactions with mentor gender. Journal of Vocational Behavior, 15(2), 193-206.

Thompsona, Lynne, Jeffries, Mike \& Topping, Keith (2010). E-mentoring for e-learning development. Innovations in Education and Teaching International, 47(3), 305-315.

Turban, Daniel B. \& Lee, Felissa K. (2013). The role of personality in mentoring relationships. In: Ragins, Belle Rose \& Kram, Kathy E. The handbook of mentoring at work: theory, research and practice (pp. 21-50). Thousand Oaks: Sage.

Vergara, S. C. (2007). Estreitando relacionamentos na educação a distância. Cadernos EBAPE.BR, v. 5, ed. especial, p. 1-8, jan.

Whiting, Vicki \& Janasz, Suzanne (2004). Mentoring in the 21st century: using the internet to build skills and networks. Journal of Management Education, 28(3), 275-293.

Zey, M. G. (1991). The mentor connection: strategy and alliances in corporate life. Transaction Publishers: New Brunswick. 